\title{
O Plano de Gestão da Área de Proteção Ambiental do Delta do Parnaíba no contexto do município de Tutóia - MA (Brasil)
}

\author{
The Management Process of Area Environmental Protection of the Delta Parnaiba in the \\ context of the municipality of Tutóia - MA (Brazil)
}

\section{LOUZEIRO $^{1}$, A. S.; FEITOSA ${ }^{2}$, A. C.}

andreza_louzeiro@hotmail.com

\begin{abstract}
Resumo
Unidades de Conservação são áreas que possuem recursos e características naturais relevantes, com vistas à proteção do ambiente. Neste trabalho, dá-se ênfase na Área de Proteção Ambiental do Delta do Parnaíba no município de Tutóia MA (Brasil), a qual vem passando por uma dinâmica que afeta diretamente a manutenção de seus atributos físicos. Neste sentido, este estudo tem como objetivo analisar as ações previstas no Plano de Gestão da APA do Delta do Parnaíba e sua atual situação no processo de gerenciamento proposto neste documento. Para dar sustentação à essa equipe, a abordagem Geossistêmica se mostrou de fundamental importância, pois a partir deste enfoque é possível realizar a análise de elementos físicos e antrópicos numa determinada área e como eles atuam no espaço.
\end{abstract}

Palavras-chave: Plano de Gestão, Área de Proteção Ambiental, Tutóia - MA.

\begin{abstract}
Conservation units are áreas that have resources and features natural relevant, in order to protect the environment. In this work, it is emphasized in the Área of Environmental Protection of the Delta Parnaíba in the municipality of Tutóia - MA (Brazil), which comes through a dynamics that directly affects the maintenance of their physical attributes. In this sense, this study aims to analyze the actions provided for in management plan of APA the Delta Parnaíba and his current situation in the management process proposed in this document. To give support to this study, the geosystemic approach proved of de fundamental importance, because from this approach it is possible perform the analysis of physical elements and anthropic in a determined area and how they act in space. Keywords: Management Plan; Area of Environmental Protection; Tutóia - MA.
\end{abstract}

Keywords: Management Plan, Environmental Protection Area, Tutóia - MA.

\section{INTRODUÇÃO}

A proteção ambiental implica o estabelecimento de leis para controlar a utilização desenfreada dos recursos naturais, cabendo destacar várias ações pioneiras que serviram de exemplo por todo o mundo com vistas a esse propósito, onde Alcântara (2006) destaca a sanção da lei de proteção da Floresta da Tijuca no Rio de Janeiro em 1861 pelo imperador D. Pedro I, uma floresta urbana que estava então degradada; em 1863, o Parlamento Inglês aprovou o Alkali Act, primeira lei ambiental, para regular a emissão de poluentes do ar pela indústria do vidro da época e, em 1872, a criação do primeiro parque nacional - o Parque Yellowstone, nos Estados Unidos da América.

Neste sentido, no Brasil foi concretizado leis que regessem as áreas consideradas legalmente protegidas, as quais são de grande relevância, tais como o Novo Código Florestal Brasileiro, Lei dos Crimes Ambientais, Política Nacional dos Resíduos Sólidos, Lei dos Recursos Hídricos, dentre outros. Com relação à diretrizes a serem seguidas, destaca-se o Sistema Nacional de Unidades de

\footnotetext{
${ }^{1}$ Andreza dos Santos Louzeiro, Programa de Pós Graduação em Geografia, Universidade Federal do Rio Grande do Norte, Natal RN, Brasil.
}

${ }^{2}$ Antonio Cordeiro Feitosa, Departamento de Geociências, Universidade Federal do Marnhão, São Luís - MA, Brasil. 
Conservação (SNUC) as Unidades de Conservação (UCs) são áreas que possuem recursos e características naturais relevantes. Estes locais são legalmente instituídos pelo Poder Público com o objetivo de conservar a sua biodiversidade através de um regime especial de administração, ao qual se aplicam garantias adequadas de proteção.

No Brasil, as UCs estão divididas em dois grupos com distintas categorias de manejo, sendo elas: Unidades de Proteção Integral (Estação Ecológica, Reserva Biológica, Parque Nacional, Parque Estadual, Monumento Natural e Refúgio de Vida Silvestre) e Unidades de Uso Sustentável (Área de Proteção Ambiental Federal, Estadual e Municipal, Área de Relevante Interesse Ecológico, Floresta Nacional, Floresta Estadual, Reserva Extrativista, Reserva de Fauna, Reserva de Desenvolvimento Sustentável e Reserva Particular do Patrimônio Natural) (SNUC, 2000).

Dentre as UCs Federais de Uso Sustentável existentes no Brasil, destaca-se neste trabalho a Área de Proteção Ambiental (APA) do Delta do Parnaíba, tal área está localizada no nordeste brasileiro e é enriquecida com uma vasta diversidade biológica. Tal APA é regulamentada pelo art. $1^{\text {o }}$ do Decreto de 28 de agosto de 1996 e compreende os Estados do Maranhão, Piauí e Ceará.

No entanto, segundo Louzeiro e Feitosa (2015) mesmo com a aprovação de legislações que visem à proteção dos recursos naturais, estas não são efetivamente implantadas, pois a maioria das unidades de proteção integral apresentam problemas de existência de terras ainda não completamente regularizadas e/ou demarcadas; falta de funcionários suficientes para fiscalizar e administrar a área; existência de planos de manejo e de gerenciamento em apenas poucas unidades ou ainda a ausência da prática das atividades desse documento.

O presente estudo tem por objetivo analisar as ações previstas no Plano de Gestão da APA do Delta do Parnaíba e sua atual situação proposta para a gestão da área. Além disso, é discutido também sobre as práticas socioambientais dos moradores de Tutóia - MA na APA do Delta do Parnaíba, município onde parte da APA está inserida e onde são realizadas atividades de sobrevivência, comercialização de excedentes e construção de infraestrutura, fato que implica no uso excessivo de recursos que até então deveriam ser preservados.

\section{METODOLOGIA}

Para dar apoio à esta pesquisa, a utilização da Teoria Geossistêmica torna-se de fundamental relevância pois a partir deste enfoque é possível realizar a análise de elementos físicos e sociais numa determinada área e como eles atuam no espaço. Sotchava (1977) já afirmava que os Geossistemas são uma classe peculiar de sistemas dinâmicos abertos e hierarquicamente organizados. Desta forma, tanto uma área elementar da superfície terrestre, como o geossistema 
planetário ou as subdivisões intermediárias do meio natural, representam uma unidade dinâmica com uma organização geográfica a ela inerente.

Ainda nesta perspectiva, o francês Georges Bertrand (2004) otimiza o conceito de Sotchava (1977) e dá à abordagem geossistêmica, uma conotação mais precisa, estabelecendo uma tipologia espaço-temporal compatível com a escala socioeconômica, enfocando as potencialidades ecológicas, exploração biológica e ação antrópica enquanto seus principais conformadores, além de considerar a teoria da bio-resistasia do pedólogo alemão Eahart, relacionando a evolução dos solos à cobertura vegetal e às condições de evolução do relevo e seus processos adjuntos. Portanto, a utilização da Teoria Geossistêmica, se faz pertinente nesta pesquisa devido a dimensão da sua abordagem, pois relaciona os fatores clima e geomorfologia (potencial ecológico) e vegetação e solo (exploração biológica) com a ação antrópica.

As investigações também apoiaram o diagnóstico da percepção ambiental e da paisagem, pois segundo Louzeiro e Feitosa (2015) para que se possa analisar se uma área está sendo alterada é interessante detectar a percepção ambiental da população moradora para que se conheçam seus valores, atitudes, condutas e como a dinâmica ambiental influenciam nas suas percepções.

Para analisar as características sociais e identificar as atividades humanas que prejudicam o ecossistema da APA do Delta no município de Tutóia, foi utilizada também a abordagem survey, a qual, segundo Noronha (2007) consiste no levantamento de informações de uma amostragem representativa a fim de obter dados sobre as características da população que representam, bem como suas ações.

Levando em consideração os pressupostos contidos na Teoria supracitada, foram necessários:

- Pesquisa bibliográfica referente ao planejamento e gestão de UCs e sobre a APA do Delta do Parnaíba;

- Realização de quatro jornadas de campo na área de estudo, com o objetivo de levantar informações socioambientais e de gestão junto à prefeitura, sindicatos e demais órgãos locais; fazer o registro fotográfico dos povoados do município;

- Elaboração e realização de entrevistas com os moradores locais, com base na técnica survey, com a finalidade de compreender a percepção ambiental dos mesmos. Para alcançar esta estada da pesquisa, foram necessários:

a) uma amostragem de 10 questionários por povoado visitado, onde foram abordadas pessoas com idade entre 15 e 65 anos. Foram feitas perguntas relacionadas à relação que a população tem com o ambiente em que vivem; 
b) visita em dez povoados que fazem parte da APA do Delta do Parnaíba no município de Tutóia, tais localidades foram selecionadas de acordo com a distância entre si para que a proximidade entre os povoados não influenciasse nas respostas dadas.

c) aplicação de 30 questionários na sede do município de Tutóia que foram realizados em cinco bairros do local, os quais foram selecionadas a partir da densidade populacional de cada um, foram eles: Centro (10 questionários), São José e Barra (7 questionários), Os Félix e Monte Castelo (3 questionários).

- Elaboração de dois mapas de uso e ocupação da terra na APA do Delta do Parnaíba no município de Tutóia dos anos de 2000 e 2013, com a finalidade de comparar as alterações antrópicas sofridas durante os treze conforme o fluxograma (Figura 01).

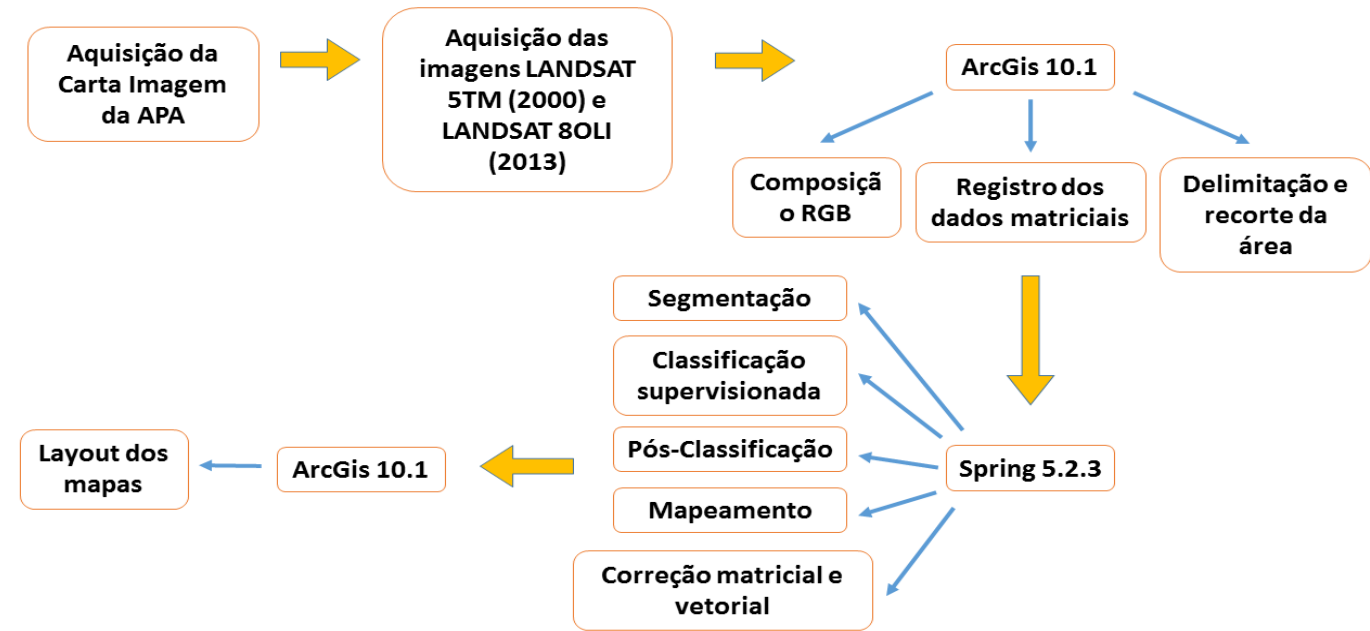

Figura 01: Fluxograma das técnicas de sensoriamento remoto utilizadas para a classificação do uso e ocupação da terra na área. Fonte: Adaptado de Louzeiro e Feitosa (2015).

\section{RESULTADOS E DISCUSSÃO}

3.1 Localização e situação geográfica da área de pesquisa

O município de Tutóia está situado a nordeste do Estado do Maranhão e segundo MDA e SDT (2005) em 2003, foi dado o primeiro passo para a constituição do território do Baixo Parnaíba, onde, dentre outros municípios, Tutóia está inserido. A área corresponde à APA do Delta do Parnaíba no município de Tutóia o qual possui seu território na região leste do MA (Figura 02).

A área em questão possui uma dinâmica natural típica de litoral, predominando a Formação Barreiras, depósito sedimentar eólico do Quaternário formado por dunas fixas e móveis e Depósitos Flúvio-aluvionais. Sua geomorfologia é formada pela planície litorânea modelada por processos marinhos. Os tipos de vegetação presentes na APA do Delta do Parnaíba apresentam características decorrentes das variações da composição edáfica e da profundidade do lençol freático. A área de 
estudo ainda possui uma dinâmica considerável no que diz respeito às Planícies Fluvial e Lacustre, a qual é formada por rios e lagos distribuídos por todo o território tutoiense. Aliado a isso, o reconhecimento dos atributos pedológicas também se fazem necessárias pois está intimamente ligada ao material litológico, às características geomorfológicas e hidrográficas, onde destaca-se as areias quartzosas, planossolos e latossoslos (CAVALCANTI, 1996; SOAVINSK, 1998; CAVALCANTI, 2004; LOUZEIRO e FEITOSA, 2015).

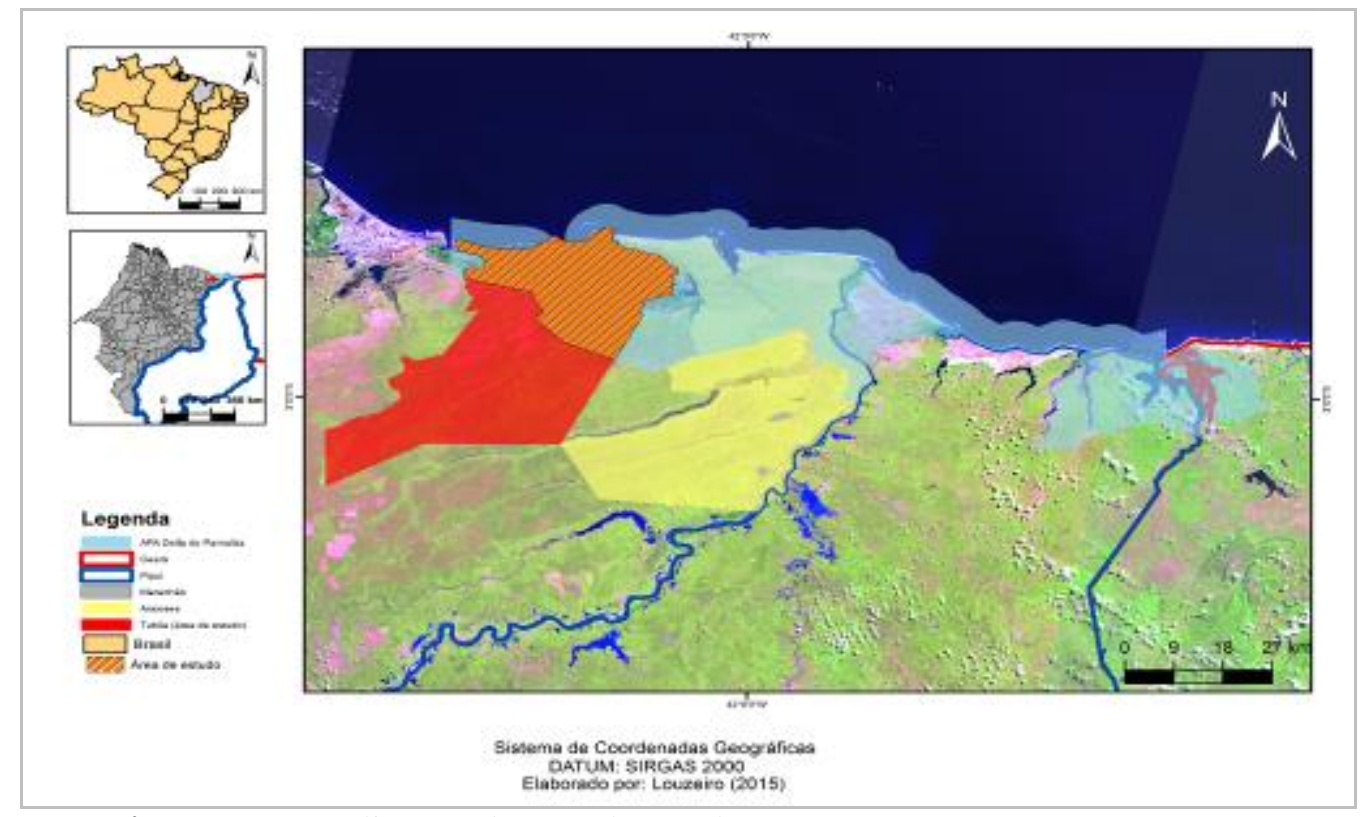

Figura 02: Localização da área de estudo. Base: IBGE, 2010. NASA, 2013.

\subsection{Planejamento e Gestão na APA do Delta do Parnaíba no município de Tutóia - MA}

Para que uma APA tenha seus recursos naturais garantidos são necessários instrumentos de gestão com o objetivo de alcançar a efetividade do equilíbrio ecológico neste ambiente. Neste sentido, cabe ressaltar os instrumentos necessários para este fim, os quais são Zoneamento Ambiental, Plano de Manejo; Monitoramento, Avaliação e Fiscalização Ambiental e a Educação Ambiental e Gestão Participativa e Plano de Gestão, onde nesta pesquisa enfatiza-se este último na APA do Delta do Parnaíba e sua efetividade no município de Tutóia.

A APA do Delta do Parnaíba possui o Plano de Gestão e Diagnóstico Geoambiental e Socioeconômico, o qual é um documento que foi criado com o objetivo de fazer com que os moradores locais e o governo atuem conjuntamente no processo de gestão da área. Este Plano baseia-se ainda nas especificidades ambientais do local e nas aspirações de desenvolvimento da população, compatibilizando estes fatores de forma sustentada e incluindo instrumentos de gestão que envolva os aspectos sociais, culturais e ecológicos da área (LOUZEIRO e FEITOSA, 2015).

Neste Plano foi criada uma Matriz de Problematização (Figura 02), quadro onde foram elencados vinte e sete problemas, os quais daremos destaque a apenas seis destes. Na Matriz são 
destacados os objetivos a serem alcançado frente à problemática e as ações propostas com vistas a solucionar o quesito levantado. Neste mesmo documento existe também o Plano de Ação (Figura 03), quadro onde foram especificadas as mesmas ações, o grau de prioridade de cada uma, os colaboradores e responsáveis por aquela ação e os resultados esperados.

\begin{tabular}{|c|c|c|}
\hline \multicolumn{3}{|c|}{ MATRIZ DE PROBLEMATIZAÇÃO VERSUS DEFINIÇÃO DAS AÇÕES } \\
\hline PROBLEMAS & OBJETIVOS & AÇÕES PROPOSTAS \\
\hline $\begin{array}{l}\text { Desmatamento e } \\
\text { queimadas indiscriminadas } \\
\text { e/ou desordenadas. }\end{array}$ & $\begin{array}{l}\text { Recursos florestais } \\
\text { manejados } \\
\text { adequadamente e } \\
\text { queimadas controladas. }\end{array}$ & $\begin{array}{l}\text {-Elaborar e implementar um programa de manejo florestal } \\
\text { sustentável; } \\
\text {-Criar hortos florestais para a produção de espécies nativas; } \\
\text {-Orientar e educar os produtores rurais no controle das } \\
\text { queimadas; } \\
\text {-Criar brigadas de incêndio florestal. }\end{array}$ \\
\hline $\begin{array}{l}\text { Uso e ocupação } \\
\text { desordenada da terra. }\end{array}$ & $\begin{array}{l}\text { Regulamentação e } \\
\text { ordenamento do uso e } \\
\text { ocupação do solo. }\end{array}$ & $\begin{array}{l}\text {-Regulamentar, ordenar o uso e ocupação do solo; } \\
\text {-Criar e implantar plano diretor para a área urbana. }\end{array}$ \\
\hline $\begin{array}{c}\text { Abastecimento e } \\
\text { saneamento básico } \\
\text { deficiente e/ou inexistente. }\end{array}$ & $\begin{array}{c}\text { Abastecimento e } \\
\text { saneamento básico } \\
\text { implantados e eficientes. }\end{array}$ & $\begin{array}{l}\text {-Elaborar e implementar um programa de abastecimento e } \\
\text { saneamento básico, compreendendo: rede de esgoto, aterro } \\
\text { sanitário, rede de água tratada, reciclagem de lixo, } \\
\text { matadouro municipal e incineração de lixo hospitalar. }\end{array}$ \\
\hline $\begin{array}{l}\text { Zoneamento ambiental } \\
\text { inexistente. }\end{array}$ & $\begin{array}{l}\text { Zoneamento ambiental } \\
\text { realizado. }\end{array}$ & -Realizar o zoneamento ambiental da APA. \\
\hline Migração de dunas. & $\begin{array}{l}\text { Migração de dunas } \\
\text { controladas. }\end{array}$ & $\begin{array}{c}\text {-Aplicar técnicas adequadas para controlar a migração das } \\
\text { dunas. }\end{array}$ \\
\hline $\begin{array}{l}\text { APA com divulgação } \\
\text { insuficiente. }\end{array}$ & $\begin{array}{l}\text { APA do Delta do } \\
\text { Parnaíba conhecida, } \\
\text { valorizada e respeitada. }\end{array}$ & $\begin{array}{c}\text {-Elaborar e implementar programa de divulgação e } \\
\text { valorização da APA. }\end{array}$ \\
\hline
\end{tabular}

Figura 02: Matriz de Problematização da APA do Delta do Parnaíba. Fonte: Adaptado de Soavinsk (1998)

\begin{tabular}{|c|c|c|c|}
\hline \multicolumn{4}{|c|}{ PLANO DE AÇÃO } \\
\hline AÇÕES & $\begin{array}{l}\text { PRIORI } \\
\text { DADE }\end{array}$ & $\begin{array}{l}\text { RESPONSÁVEIS E } \\
\text { COLABORADORES }\end{array}$ & RESULTADOS ESPERADOS \\
\hline $\begin{array}{l}\text { Realizar zoneamento } \\
\text { ambiental na APA }\end{array}$ & 2 & $\begin{array}{c}\text {-IBAMA, -ONG'S, -Universidades } \\
\text {-Secretaria Estadual de Meio Ambiente }\end{array}$ & $\begin{array}{l}\text { Desenvolvimento sustentado da } \\
\text { região }\end{array}$ \\
\hline $\begin{array}{c}\text { Elaborar e } \\
\text { implementar um } \\
\text { programa de } \\
\text { abastecimento de água } \\
\text { e saneamento básico }\end{array}$ & 3 & $\begin{array}{l}\text {-Secretaria Estadual de Recursos Hídricos } \\
\text {-Companhia Estaduais de Águas, Esgotos e } \\
\text { saneamentos. } \\
\text {-Secretarias Estaduais de Obras } \\
\text {-Secretarias Estaduais de Saúde. }\end{array}$ & $\begin{array}{l}\text { Implantação de obras de } \\
\text { saneamento básico urbano e rural }\end{array}$ \\
\hline $\begin{array}{c}\text { Elaborar e } \\
\text { implementar programa } \\
\text { de divulgação e } \\
\text { valorização da APA }\end{array}$ & 10 & $\begin{array}{l}\text {-Prefeituras Municipais, -ONG's } \\
\text {-Secretarias Estaduais do Meio Ambiente }\end{array}$ & APA divulgada e valorizada \\
\hline $\begin{array}{l}\text { Regulamentar, ordenar } \\
\text { e controlar o uso e } \\
\text { ocupação da terra. }\end{array}$ & 19 & $\begin{array}{l}\text {-Secretarias Municipais, -ONG's } \\
\text {-Universidades, -INCRA }\end{array}$ & $\begin{array}{l}\text { Redução do usos indevido do } \\
\text { solo }\end{array}$ \\
\hline $\begin{array}{c}\text { Restaurar, recuperar e } \\
\text { reabilitar as áreas } \\
\text { degradadas. }\end{array}$ & 21 & $\begin{array}{l}\text {-IBAMA, -Universidades, -Prefeituras } \\
\text {-Secretarias Estaduais de Meio Ambiente }\end{array}$ & $\begin{array}{c}\text { Preservação do patrimônio } \\
\text { natural, histórico e cultural da } \\
\text { APA }\end{array}$ \\
\hline $\begin{array}{c}\text { Aplicar técnicas } \\
\text { adequadas para } \\
\text { controlar a migração de } \\
\text { dunas }\end{array}$ & 26 & $\begin{array}{c}\text {-IBAMA, -Prefeituras Municipais } \\
\text {-Secretarias Estaduais de Meio Ambiente }\end{array}$ & Controle da migração de dunas \\
\hline
\end{tabular}

Figura 03: Plano de Ação da APA do Delta do Parnaíba. Fonte: Adaptado de Soavinsk (1998) 
Esses quadros foram elaborados em 1998 e todas as ações estavam previstas para serem consumadas até o ano 2000, pois o próprio Plano de Gestão estipula essa data, onde o Instituto Brasileiro de Meio Ambiente e Recursos Naturais Renováveis (IBAMA) do Estado do Ceará é tido como instituição coordenadora de todas as ações predefinidas. Sendo assim, foi possível analisar cada problema e cada ação descritos nos Planos de Ação e na Matriz de Problematização, além disso analisar o estado atual de cada uma.

Observando os quadros pode-se afirmar que poucos desses problemas foram solucionados, a começar pela elaboração do Zoneamento Ambiental da APA. Este instrumento de gestão até o presente momento não foi publicado e se existe não está disponível para acesso público, sendo que esta é uma das atitudes primordiais que deveria ser providenciada de modo que a APA pudesse ser melhor gerida (LOUZEIRO e FEITOSA, 2015). Neste sentido, Soavinsk (1998) ainda acrescenta que uma das questões debatidas no momento da criação do Plano de Ação foi a necessidade de se realizar o seu zoneamento ambiental, como forma de viabilizar a administração de modo eficaz, com o manejo adequado dos recursos naturais e o atendimento das demandas socioambientais mais importantes para a região.

Outra ação que ainda não teve seus objetivos alcançados, principalmente para os moradores dos povoados existentes dentro da APA no município de Tutóia, é a falta de saneamento básico no município. Uma grande porcentagem das famílias depende de um sistema de abastecimento de água e saneamento básico insuficientes para uma qualidade de vida aceitável (Gráficos 04 e 05). Muitos alegam que a água em duas localidades não é limpa, sendo necessário buscar em outro povoado, pois alegam que a água do local em que vivem é poluída (LOUZEIRO e FEITOSA, 2015).

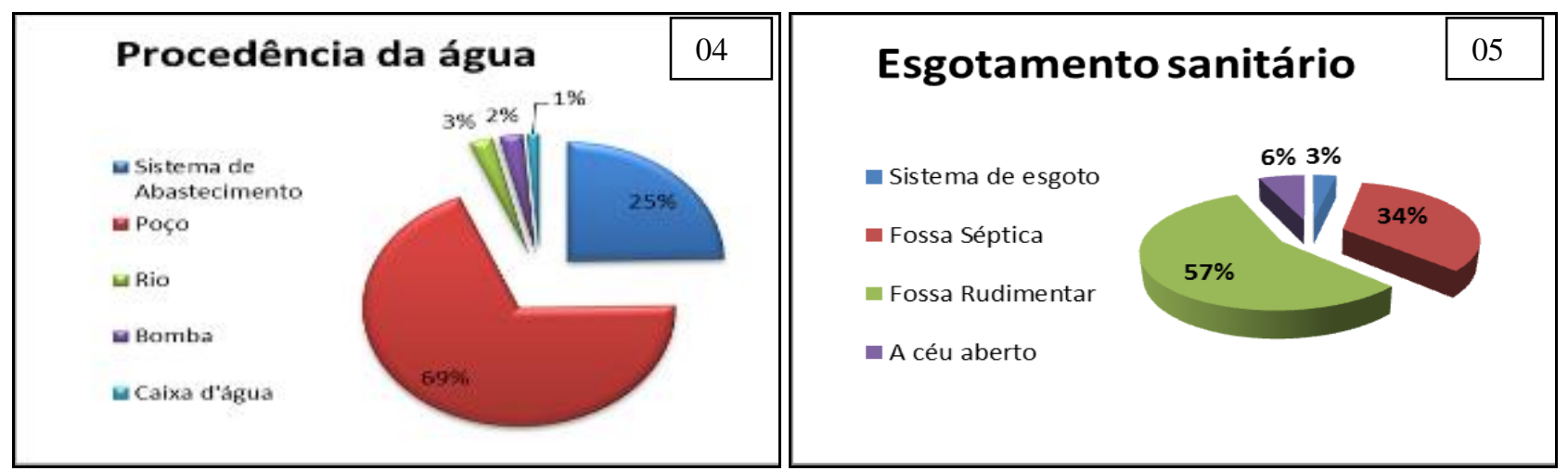

Figuras 04 e 05: Procedência da água e esgotamento sanitário dos povoados Fonte: Louzeiro e Feitosa (2015).

No que tange à divulgação da APA, pode-se afirmar que ainda não foi alcançada em Tutóia, visto que, em entrevista, 74\% dos entrevistados declarou que não conhece a APA do Delta do Parnaíba e 56\% alegaram não saber a serventia de uma APA, tal fato denota que a divulgação sobre a existência e objetivo de criação da UC em questão não foi eficiente no município. 
Outro fator diz respeito ao uso e ocupação da terra em Tutóia, o qual têm aumentado no decorrer dos anos, principalmente na sede do município. A partir daí, infere-se que as medidas de recuperação de áreas degradadas neste local não surtiram o efeito esperado, pois é possível observar a urbanização em áreas que deveriam estar preservadas (LOUZEIRO e FEITOSA, 2015).

O ano de 2000 (Figura 06) foi o segundo depois da regulamentação do Plano de Gestão da APA do Delta do Parnaíba, sabendo disto, observa-se que no lugar onde se localiza a sede, havia o início de uma expansão urbana. Já em 2013 (Figura 07), percebe-se a ocupação em Áreas de Preservação Permanente e a ocupação urbana em áreas de dunas, dentre outras irregularidades.

A partir dessas observações, leva-se em consideração que a área está tendo um crescimento urbano de forma desordenada e exploratória, o que é possível perceber na quantificação dos resultados da classificação dos mapas (Tabela 01). Tal fato desobedece aos padrões ambientais para Áreas de Proteção Ambiental e Áreas de Preservação Permanente, os quais estão explícitos nas legislações que regem estes tipos de ambientes.
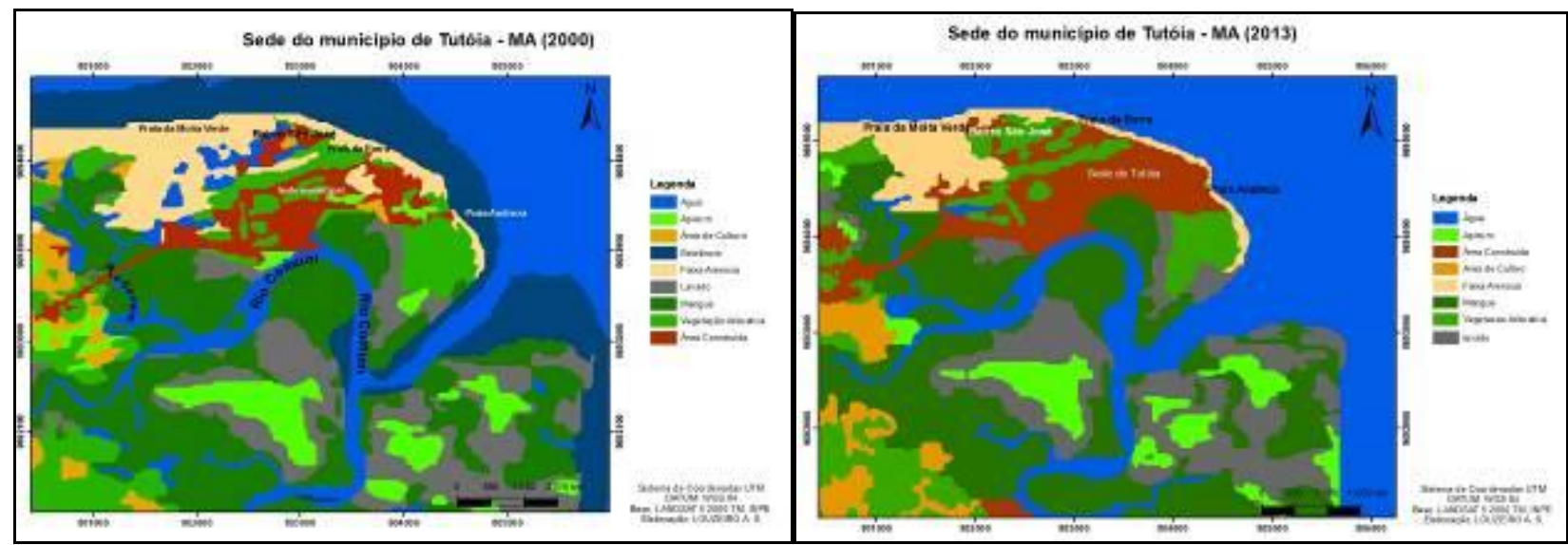

Figuras 06 e 07: Sede do município de Tutóia nos anos de 2000 e 2010. Fonte: Louzeiro e Feitosa (2015)

Tabela 01: Quantificação das áreas afetadas nos anos de 2000 e 2013. Fonte: Louzeiro e Feitosa (2015)

\begin{tabular}{cccc}
\hline Área/Ano & $\mathbf{2 0 0 0}\left(\mathbf{k m}^{\mathbf{2}}\right)$ & $\left.\mathbf{2 0 1 3} \mathbf{( k m}^{\mathbf{2}}\right)$ & $\begin{array}{c}\text { Diferenciação } \\
(\mathbf{k m})\end{array}$ \\
\hline Área construída & 1.237 & 2.104 & +867 \\
Faixa arenosa & 1.282 & 1.258 & -24 \\
Mangue & 6.400 & 6.782 & -386 \\
Vegetação arbustiva & 2.811 & 2.388 & -423 \\
Área de cultivo & 0,746 & 1.034 & +288 \\
Recursos hídricos & 18.871 & 17.806 & -1.065 \\
\hline
\end{tabular}

No que tange à migração de dunas, infere-se que nas proximidades da sede do município, as medidas mitigadoras feitas pelos próprios moradores não surtiram efeito, visto que as casas estão instaladas em áreas de dunas móveis (Fotos 08, 09 e 10). Nestes locais, a movimentação dunar se 
tornou um risco para a população, pois os sedimentos arenosos invadem as casas dos moradores. Essa dinâmica compromete a qualidade de vida da população residente pois os mesmos não possuem outro lugar para morar. Eles dependem dos recursos naturais para desenvolver suas atividades de subsistência e, consequentemente, ficam suscetíveis à dinâmica natural da área.

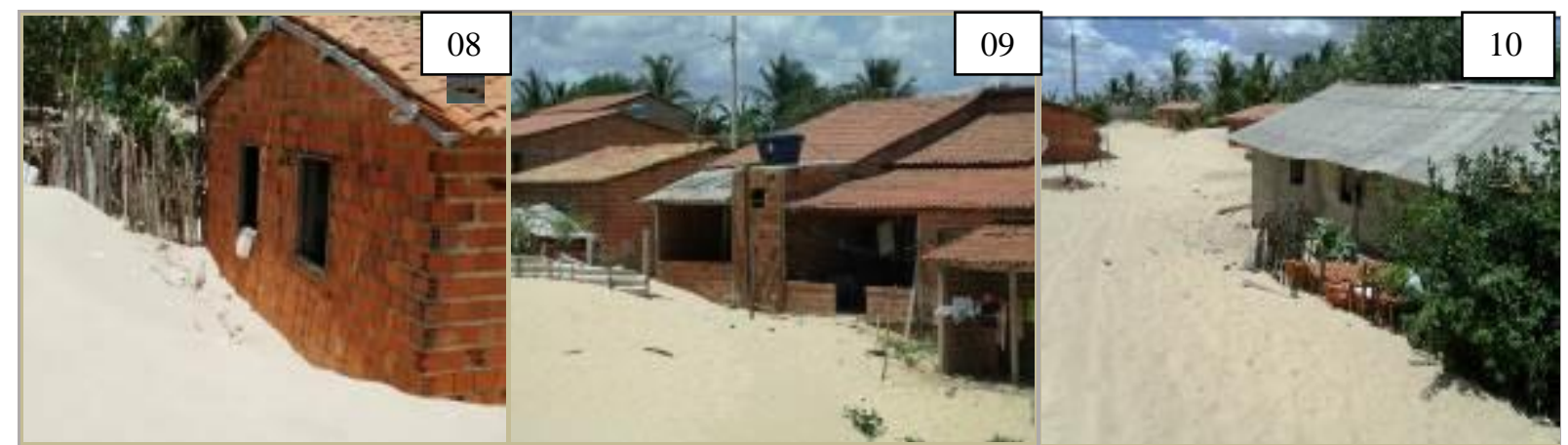

Fotos 08, 09 e 10: Residências inseridas em áreas de dunas móveis. Bairro São José. Fonte: Louzeiro e Feitosa, 2015.

Além de todos esses problemas apontados, outra situação preocupante e algo de deveria ser uma das primeiras prioridades é a ausência de um Plano de Manejo da APA. Este documento auxilia na parte mais prática do processo de gestão de qualquer UC e é um instrumento que já deveria existir desde o ano de o ano de 2001, pois de acordo com a Lei № 9985, a exigência de elaboração de Planos de Manejo para todas as UCs é num prazo de 5 anos a partir da data de criação da mesma.

Contudo, segundo Louzeiro e Feitosa (2015) a APA do Delta do Parnaíba não possui um Plano de Manejo, o que a área dispõe é do Plano de Gestão, os quais são documentos com características semelhantes, mas com objetivos distintos. Aquele tem como objetivo principal estabelecer o zoneamento da UC e as normas que devem presidir seu uso e o manejo dos seus recursos naturais, inclusive a implantação de estruturas físicas necessárias à gestão da unidade e fazer com que a mesma seja protegida por lei e os objetivos estabelecidos na sua criação sejam alcançados (SNUC, 2000).

\section{CONSIDERAÇÕES FINAIS}

Através desse estudo percebeu-se que a APA do Delta do Parnaíba no município de Tutóia vem sofrendo grandes alterações ambientais devido às atividades de comércio, construção de casas e asfaltamento de estradas, tais ações são responsáveis pela retirada da cobertura vegetal, aumento do número de vias de acesso e diminuição de mangues nas margens dos corpos hídricos. Pode-se afirmar que tais problemas estão relacionados a falta de planejamento e fiscalização adequados na área, o que implica a intensificação das áreas urbanizadas em locais onde a proteção é mais 
acentuada, como por exemplo as margens de rios, poluição dos recursos hídricos, supressão da cobertura vegetal, etc.

Nesse contexto, o que pode ser notado é a ausência de um adequado planejamento ambiental para subsidiar cada município quem compõe a APA, especialmente os do Estado do Maranhão, pois é perceptível o não cumprimento dos objetivos propostos pelo Plano de Gestão. Outro fator que dificulta ainda mais a proteção do local é a falta de conhecimento da população de que moram em uma área protegida, os quais, se tivessem o mínimo de treinamento básico, serviriam como agentes fiscalizadores da área. Além disso, a ausência do Plano de Manejo e do Zoneamento Ambiental da Unidade atenuam ainda mais a ineficácia do seu gerenciamento.

\section{REFERENCIAS}

ALCÂNTARA, C. M. M. O Despertar da Consciência Ambiental nas Empresas: o surgimento do Gerenciamento Ecológico. Anais do XIII Simpósio de Excelência e Gestão em Tecnologia. Ano 2006, Resende- RJ, 2006. p. 296-316 296.

BRASIL. Decreto de 28 de agosto de 1996. Dispõe sobre a criação da Área de Proteção Ambiental Delta do Parnaíba, nos Estados do Piauí, Maranhão, e Ceará, e dá outras providências, 1996.

BERTRAND, G. Paisagem e Geografia física global. Esboço Metodológico. Tradução: Olga Cruz. Trabalho publicado, originalmente, na "Revue Geógraphique des Pyrénées et du Sud-Ouest", Toulouse, v. 39 n. 3, p. 249-272, 1968, sob título: Paysage et geographie physique globale. Esquisse méthodologique. Publicado no Brasil no Caderno de Ciências da Terra. Instituto de Geografia da Universidade de São Paulo, n. 13, 1972. Revista RA`E GA, Editora UFPR, Curitiba, n. 8, p. 141$152,2004$.

CAVALCANTI, A. B. Caracterização e análise das unidades geoambientais na planície deltaica do rio Parnaíba / PI. Dissertação apresentada ao Programa de Pós-Graduação em Geografia. Rio Claro: UNESP / IGCE. 1996, 120p.

CAVALCANTI, A. B. Análise integrada das unidades paisagísticas na planície deltaica do rio Parnaíba - Piauí/Maranhão. Mercator - Revista de Geografia da UFC, 3(6): 105-118, 2004.

SOAVINSKI, Ricardo José. Plano de Gestão e Diagnóstico Geoambiental e socioeconômico da APA do Delta do Parnaíba. Instituto de Estudos e Pesquisas Sociais da UECE-IEPS, 1998. 98p. SOTCHAVA, V. B. O Estudo de Geossistemas. Instituto de Geografia. USP, São Paulo: Ed. Lunar, 1977.

LOUZEIRO, A. S. e FEITOSA, A. C. Diagnóstico do município de Tutóia - MA frente ao processo de planejamento e Gestão. Monografia apresentada ao curso de Geografia da Universidade Federal do Maranhão. São Luís, 2016. 76p.

MDA - Ministério de Desenvolvimento Agrário. SDT - Secretaria de Desenvolvimento Territorial Território Baixo Parnaíba. Plano Territorial de Desenvolvimento Rural Sustentável, São Luís, 2005.

SNUC - Sistema Nacional de Unidades de Conservação: texto da Lei 9.985 de 18 de julho de 2000 e vetos da presidência da República ao PL aprovado pelo congresso Nacional. São Paulo: Conselho Nacional da Reserva da Biosfera da Mata Atlântica, $2^{a}$ edição ampliada, 2000. 
Recebido em: 14/08/2016

Aceito para publicação em: 01/10/2016 